\title{
Research on the application of flipped classroom teaching mode of in the course of in the course of Chinese
}

\author{
Guijie $W u^{1}$ \\ ${ }^{1}$ Beijing Information Technology College Beijing 100070
}

Keywords: Flipped classroom; Chinese teaching mode

\begin{abstract}
The development of information technology brings challenges to the traditional classroom teaching mode, flipped classroom provides a new idea for the organic integration of classroom teaching and information technology, combining with the teaching practice of "Chinese" Curriculum Teaching "in accordance with the basic process of turning students look ahead of material practice -- teachers guidance -- Summary and promotion", explore the "language" the course of flipping the classroom teaching mode.
\end{abstract}

The advantage of turning over the classroom compared with the traditional classroom teaching

At present, scholars at home and abroad will be divided into two stages: classroom and classroom. The basic teaching process of the flipped classroom is "student look ahead of material practice -the guidance of teachers, summed to enhance this process, and the traditional classroom" Preview lectures - practice "is quite different in the study design and teaching organization, The difference is shown in the table:

Table1 Comparison of learning mode of traditional classroom and flipped classroom

\begin{tabular}{|l|l|l|}
\hline & Traditional classroom & Flipped Classroom \\
\hline Teacher & $\begin{array}{l}\text { Knowledge explaining and } \\
\text { organizing classroom teaching }\end{array}$ & $\begin{array}{l}\text { Guide learning, transfer and } \\
\text { promotion }\end{array}$ \\
\hline Student & Passive acceptance & Initiative inquiry \\
\hline Teaching form & $\begin{array}{l}\text { Classroom learning + after class } \\
\text { consolidation }\end{array}$ & $\begin{array}{l}\text { Research in the course of } \\
\text { pre class test }\end{array}$ \\
\hline Classroom content & Teaching knowledge content & Problem Inquiry \\
\hline Application & Display content & $\begin{array}{l}\text { Autonomous learning, } \\
\text { interaction, communication } \\
\text { and collaboration }\end{array}$ \\
\hline Technology & Traditional paper test & Process and multi dimension \\
\hline
\end{tabular}

\section{Research on the application of flipped classroom model in "Chinese" course}

Design of flip classroom teaching mode based on the idea of the task, and teachers through in-depth communication, combined with the teaching goal, selected suitable for turning the contents of teaching mode, combined with the daily teaching experience accumulated to write "occupation communication" course design, teaching content will be decomposed into practical tasks in class 
implementation before class, teaching environment, teaching flow diagram .

\section{Before class}

Students' autonomous learning before class. The method and process of learning students according to the teaching task list given in, after watching the video, the students should finish the exercises assigned by the teacher before class, consolidate the learning content, teachers through the students' test found difficulty, in the course of targeted strengthening.

Discussion on the autonomous learning process before class. Before the course of the autonomous learning, teachers can use information technology to provide network communication platform. Between teachers and students can through the QQ exchange group, chat rooms, network learning platform and other forms of mutual assistance between teachers and students, or between students.

\section{In the course of}

"Lead" -- put forward the task. The problems in the class are determined by the teachers and students. The main task of class teachers is analyzed and reported according to the learning situation of students before class, master students in the horizontal comparison, combined with the students' learning situation, proposed the key to solve the difficulties in teaching; students' main task is based on the course of study situation question, solve communication. Comprehensive teachers and students to determine the specific circumstances of the classroom to explore the main issues, the introduction of the content of the new class teaching, and put forward a new task to lead students to explore the problem of the problem.

"Inquiry" -- design scheme to carry out collaborative inquiry activities. Considering the different characteristics of teacher students divide students into $3 \sim 5$ group, each group of students to elect a leader, and then assigned to each group of inquiry learning tasks, team members according to the relevant tasks of discussion. Inquiry activities leader do dynamic learning records, each team member should actively discuss, speak, team members by brainstorming and group discussion learning through active exchanges and cooperation to complete the task, to achieve learning objectives. In the process, teachers need to capture the inquiry of the team and guide them in time.

"Do" - task implementation. After the students have an independent problem solving, collaborative inquiry activities between the groups, the results of the individual and group to be displayed in the classroom. Take the form of presentation, presentation, small competitions, and the exchange between the groups and comments and share learning gains.

"Review" - summary evaluation. Feedback evaluation is an important part of the flipped classroom teaching mode, teacher evaluation through the feedback of students' learning, help students establish confidence of learning, let the students to discover the joy of learning, and be more actively into learning. The flipping classroom evaluation system is a multi dimension and multi way, reflected in the following aspects: the evaluation of members is not only teachers, parents, peers, learners have become members of the evaluation at this time; the evaluation includes the course before the targeted practice learning and inquiry learning in the classroom, the problem the ability of solving problems independently, in the group of collaborative inquiry tasks and results in the display and other aspects of the performance. The evaluation result of these feedback is the basis for teachers to make the next step of teaching plan and to determine the next lesson.

"Extension" - task development. To expand and to play in our "language" in the teaching of the migration effect can not be ignored, to promote students' learning transfer, first set the effective 
expansion of basic knowledge, grasp the teaching task. Make full use of typical cases, to provide students with enough practice and application opportunities, so that students really grasp the connotation of knowledge, application principles and basic methods. As a teacher, we need to contact analysis of the real life of students, expand and transfer of effective and feasible, as clear to play a guiding role in the process of teaching, teaching and educating people closely together, to promote the students' understanding of knowledge, deepen the knowledge understanding, enhance the application of knowledge transfer ability

\section{Results of research}

In the course of "Chinese", the experiment teaching of the flipped classroom teaching mode has been tested by the practice of one semester, and has achieved remarkable results. Compared with the previous students, students in the experimental class in the "language" of the theoretical understanding and practical ability has been improved greatly. Through the course of a school year and the implementation of learning activities, the students of the experimental class have better finish the task of the course in the classroom teaching, and basically achieved the teaching goal of "Chinese" course.

Flipped classroom experimental teaching model in improving the ability to learn, to help understand, deepen the knowledge and so on have a good role in promoting the survey, the relevant data show that $83.3 \%$ of the students.

That "flipped classroom" learning is helpful to their autonomous learning, this way they are very much like; only $16.7 \%$ of students believe that learning effects in general.

In the flipping classroom improve self-learning ability, 55.6\% think of flipping the classroom teaching mode is very helpful to improve the ability of independent learning, $33.3 \%$ of the students think it is more helpful; $\mathbf{1 1 . 1 \%}$ learners to understand and deepen the knowledge to help the general situation.

In the aspect of knowledge internalization advantage survey data show that $48.3 \%$ of the students think through inquiry learning knowledge more firmly, 28.9\% of the students think that this method can stimulate their interest in learning, make the knowledge keep for a long time, $27.3 \%$ of the students think that can stimulate interest in learning.

Conclusion: by turning the mode of classroom teaching application in the "language" in the curriculum, teaching mode, learning tasks turn before class in the course of the typical tasks and after the expansion of the task to realize the knowledge transfer (skills), knowledge (skills) and construct knowledge internalization, consolidate and expand (skills). Using this mode of teaching can improve learners' autonomous learning ability, can promote and deepen the understanding of knowledge, can stimulate learners interest in learning, to promote the internalization of knowledge; the learning results in terms of the experimental class was flipped classroom teaching mode in academic performance has been improved.

\section{Existing problems and future prospects}

In the flipped classroom teaching mode of teaching experiment, students are given a positive affirmation in the learning effect and subjective evaluation, but there are also some problems in the specific implementation, the task of teaching should be further refined, such as: task four - job interview content for the study of the common lack of recruitment interview questions design or not fully covered me college students; learning support materials for team members; equipped and individual students accept and adapt ability of implementation has great influence on the flip 
classroom teaching mode, need to do further research on the adjustment in these areas, in the future will further implement the flipped classroom and stratification, and other survey methodology. In order to solve the above problems with.

\section{References}

[1] Zhang Jinlei, Wang Ying, Zhang Baohui. Research on the flipped classroom teaching mode [J]. Journal of distance education,2012 (4): 46-51.

[2] Zhang Yueguo, Zhang Yujiang. On the flip the classroom J. The teaching of information technology in primary and middle schools Education, 2012, (3).

[3]. The Constructivism -- to reform the traditional teaching theory based J. Audio visual education Research, 1997, (3).

[4] Liao Guorong, left Tao. "Flipped classroom" of the "nitrogen hydride" instructional design [J]. small and medium Information technology education, 2012 (3): 19

[5] Jinling Salman Khan how to move toward the "flipped classroom" [J]. China information technology education, 2012, (10): 29

[6] Comparison and thinking of "flipped classroom" between China and the United States [EB/OL].

[7] Li Kedong, Zhao Jianhua. Study on the principle and application mode of blended learning [J]. audio visual education research, 2004, (07)

[8] more than Vince. On subjectivity and self learning J. Education, 2001, (12). 